\title{
Application of response surface methodology for optimizing the deodorization parameters in chemical refining of kenaf seed oil
}

\begin{abstract}
Kenaf seed oil has been suggested to be used as edible oil but there is limited information available about the optimal parameters to produce refined kenaf seed oil. Response surface methodology was used to study the effects of the temperature $\left(180-260{ }^{\circ} \mathrm{C}\right)$ and time $(0.5-$ $2.5 \mathrm{~h}$ ) in the deodorization stage of the refining process for kenaf seed oil. Free fatty acids, pAnisidine value, total color difference, and tocopherol and tocotrienol contents were measured. Well-fitting models were successfully generated for the responses of free fatty acids $(\mathrm{R} 2=0.9619, \mathrm{p}<0.0001), \mathrm{p}$-Anisidine value $(\mathrm{R} 2=0.9867, \mathrm{p}=0.0014)$, total color difference $(\mathrm{R} 2=0.9997, \mathrm{p}<0.0001)$, and tocopherol and tocotrienol contents $(\mathrm{R} 2=0.9758$, $\mathrm{p}<0.0001)$. The optimum parameters were recommended at a temperature of $220{ }^{\circ} \mathrm{C}$ and a time of $1.5 \mathrm{~h}$. These optimum parameters produced refined kenaf seed oil with free fatty acids of $0.036 \%$, peroxide value of $0 \mathrm{meq} / \mathrm{kg}, \mathrm{p}$-Anisidine value of 6.67 , color of $\mathrm{L} *=7.58$, a* $=$ $-2.48, \mathrm{~b} *=3.29$, and tocopherols and tocotrienols contents of $39.69 \mathrm{mg} / 100 \mathrm{~g}$. There were no significant differences $(\mathrm{p}>0.05$ ) between experimental and predicted values, indicating the adequacy of the well-fitting models.
\end{abstract}

Keyword: Optimization; Deodorization; Kenaf seed oil; Free fatty acids; Tocopherol and tocotrienol 